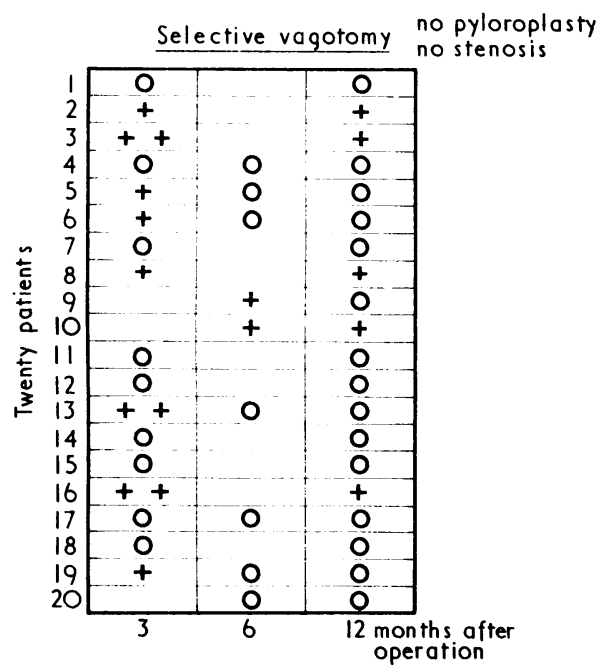

so long as nerve section is complete and the nerves of Latarjet properly preserved. It is a very much better operation than bilateral selective vagotomy without drainage for it can be used in the presence of organic duodenal narrowing. Probably only in advanced duodenal stenosis is a drainage operation required.-I am, etc.,

Harold Burge

Charing Cross Group of Hospitals, West London Hospital,

1 Amdrup, E., Amdrup Bente, M., and Griffith, Amdrup, E., Amdrup Bente, M., and Griffith,
C. A. Fourth World Congress of Gastroentero
logy. Advance Abstracts, P. 430. Griffith, C. A., and 1957 . 32,96 .

3 Johnston, D., Humphrey, C. S., and Wilkinson A. R, Proceedings of Association of Surgeons
of Great Britain and Ireland, 1970.

\section{Controlling Gastric Acid}

SrR,-Your leader "Controlling Gastric Acid" (28 November, p. 510) states "Anticholinergic drugs act by reducing vagal activity. They are fully effective only when given in doses which cause undesirable side effects such as drowsiness, dryness of the mouth blurring of vision, and difficulty with emptying the bladder." All this is true when these drugs are given in single doses. But when they are given four times a day, in the maximal dose that gives no side effects as determined by gradual escalation, the result is different. For example, Mitchell $e$ al. ${ }^{1}$ compared the reduction of acidity of the gastric contents obtained with atropine or poldine at doses that produced no side effects. The study was double blind, and the mean duration of the treatment was seven days with each drug given four times daily. The mean reduction in acidity of the gastric contents after ordinary food was $60 \%$ with atropine and about $80 \%$ or more with poldine.

Seidelin ${ }^{2}$ studied gastric secretion of acid with doses of poldine that produced no side effects. Using the augmented histamine test he found a reduction of gastric secretion of acid by $50 \%$ after the patients had been treated for about three weeks. He pointed out that the reduction was close to that achieved with the augmented histamine test after vagotomy and gastroenterostomy. Hunt and Douthwaite ${ }^{3}$ gave poldine four times a day at doses which gave no side effects; gastric secretion in response to test meals was reduced by half. These authors also noted that the full effect of poldine took up to three weeks to develop on continuous dosage.

Whether or not poldine is clinically effective is a matter of opinion." However, it does seem to be established that at doses adjusted to the patient a reduction of gastric secretion of acid by $50 \%$-nearly equal to that produced by surgical vagotomy-is commonly obtained without side effects. Moreover, increasing the dose to that which gives side effects does not in our experience reduce gastric secretion further

There is a substantial body of clinical opinion in favour of anticholinergic drugs such as poldine, if these are used properly. While argument continues about the scientific evidence it is unreasonable to assume that experienced clinicians are necessarily mistaking the placebo effect for pharmacological active, particularly as there are good theoretical reasons for expecting anticholinergic drugs to benefit these patients.-We are, etc., Department of Physiology,
Guy' Hospital Medical School,
London S.E.1

J. N. HuNT

Lewisham General Hospital,
London S.E.13

T. M. L. Price

1 Mitchell, R. D., Hunt, J. N., and Grossman, M. I. Gastroenterolory, 1962, 43, 400 .

2 Seidelin, R., British Medical fournal, 1961, 1, 1079. Medical fournal, 1958, 1. 1030 . J. N., British Medical fournal, 1958, 1. 1030.
Hunt, J. N., and Price, T. M. L., Practitioner 1967, 198, 156.

SIR,-With reference to your recent leading article entitled "Controlling Gastric Acid" (28 November, p. 510) we have studied the effect of an inhibitor of histamine synthesis (NSD 1055, Smith and Nephew) on canine gastric acid secreted from total gastric and Pavlov pouches. In several short-term and long-term experiments, NSD 1055 (25 mg and $100 \mathrm{mg} / \mathrm{kg}$ body weight) was administered and acid secreted in response to submaximal doses of bethanecol and pentagastrin was measured. Up to date we have been unable to demonstrate any reduction in acid output. Details of this work will be found in a paper which is now being prepared for publication.-We are, etc.,

GeORGe Dickson Crawford W. Jamieson

Surgical Unit,

Surgical Unit,
St. Mary's Hospital,
London W. 2

\section{Management of Cancer}

SIR,-Public criticism of the lack of acceptance by the medical profession of apparently encouraging responses from the Bavarian clinic of Dr. Joseph Issels is natural as a first reaction. Now that the mysterious cloak has been removed it appears that of a "random" sample of one-third of 750 cases, only a further one-third, or 88 cases, meet the requirements of accurate analysis. Of these, only $18 \%$ (16 cases) were alive at 5 years (26 December, p. 760 ).

It is now, surely, the important duty of every doctor to give information to anxious relatives and to explain what orthodox medicine can do. In a completely unselected series of patients with very advanced and recurrent breast cancer hormone control ${ }^{1}$ alone produced an objective remission in over $60 \%$ of all patients at 6 months and $50 \%$ at 1 year. With additional treatment a further half of this group without visceral metastases (one-quarter of all such cases) were living at 5 years. There is now a whole list of types of cancer with 5-year survivals, many of which were deadly to the last generation: these include $64 \%$ of liposarcomas ${ }^{2} ; 85 \%$ or more of patients with cancer of the body of the uterus ${ }^{34}$ when efficiently treated by intracavity radiation are usually free of active growth at operation, and even advanced cases do relatively well; $95 \%$ of patients with seminoma of the testis, which is supremely radiosensitive, are alive at this time. ${ }^{5}$ Advances in the treatment of malignant melanoma have produced a survival rate comparable with breast cancer-excellent in the early and far from hopeless in the advanced.

Every clinic dealing with much malignant disease has proved star cases; good examples are:

(1) 20 years' survival from metastatic bone disease in the pelvis from the breast. Some treatment has been given in the meantime but the patient is well and doing a full-time job (androgens and radiotherapy).

(2) 15 years' survival from substantial metastatic disease in bone from a recurrent thyroid cancer in the neck. This patient has just retired from an arduous full-time job and is very well (radiotherapy and thyroxine).

(3) 15 years' survival from true Hodgkin's disease, first in the neck and then five years later forming a large mass in the left groin. Now normal (radiotherapy alone)

The question is, how often can these star cases be produced? After discussion with several of my colleagues of considerable experience, the figure has been put as high as $10 \%$. Surely this is a triumph for British medicine in dealing with such advanced cases? The next question is what methods are employed in obtaining these star results, because they do not come easily. These methods include the following:

(1) Preliminary chemotherapy by intra-arterial infusion combined with the use of an isotopetimed neutralizer to spare the bone marrow and the immune state (for example, nitrogen mustard locally and thiosulphate intravenously).

(2) Chemotherapy as a preliminary to radiation $^{6}$ to render the neoplasm more vascular and smaller-and so more curable. Both, or either, of these methods may be combined with raising the oxygen concentration, either using a hyperbaric tank or giving a drip of dilute hydrogen peroxide.

(3) Surgical procedures may utilize local chemotherapy to prevent recurrence, or employ electrocoagulation destruction if complete excision should prove difficult.

(4) The use of "split course" irradiation, to take advantage of the improved vascularity during treatment and the employment of more accurate and improved methods of irradiation,? so lessening the immunological damage. 8

(5) In widely disseminated or highly undifferentiated tumours, or both, the use of systemic chemotherapy - for example, in chorionepithelioma ${ }^{9}$ or seminoma-and, as a preliminary to immunotherapy-for example, with Corynebacterium parvum vaccination.

(6) Immunotherapy by the local application of smallpox vaccine or systemically by intravenous T.A.B. with subsequent pyrexia.

(7) Careful attention to the general condition -blood transfusion; correction of metabolic defects; graduated excercises; and, most important of all, hope and encouragement.

Lastly, the vital decision is when to do 
nothing that distresses the patient; because, with a hopeless outlook, this is the correct treatment.-I am, etc.,

ANTHONY GreEN

Department of Radiotherapy,
Royal Northern Hospital,

Royal Northe

1 Green, A., British Medical fournal, 1966, 2, 951.
2 Spittle, M. F., and Newton, K. A., British fournal
of Cancer, in press. of Cancer, in press.

and Ovary, p. 188. Chicago, Year Book Medical Publishers, 1969.

Green, A., Proceedines of the Royal Society of
Medicine, 1954. 47, 907.

Rarle, J. D., Baoshaw, M. A.,
Radio'o 1968, 91. 10n8.

6 Green, A., Lancet, 1965, 1.276. 211.

Green, A., British Medical fourna!, 1969. 4. 622.

Baoshawe, K. D.. Goldina, P. R., and Orr, A. H.
British Medical fournal, 1969, 3, 733.

\section{Prolonged Therapeutic Starvation in Gross Refractory Obesity}

SIR,-The poor long-term prognosis of therapeutic starvation, its hazards, and prolonged hospitalization implied by Dr. J. F. Munro and colleagues in their article (19 December, p. 712) prompts me to suggest the alternative use of intestinal shunt in suitable cases of gross intractable obesity. This oneration has been used for more than ten years by Payne and DeWind ${ }^{1}$ and others in the U.S.A. Personal experience with this procedure is illustrated by the following case report.

The patient was a 46-year-old mother of three children, who had been dieting for three years. Durine that period she had gained $7 \mathrm{lb}$ $(3 \mathrm{~kg})$ in weight to $274 \mathrm{lb}(124 \mathrm{~kg})$. Her height is 62 in $(2.1 \mathrm{~m})$. She presented because she was ashamed of her gross appearance and because of shortness of breath, backache, and poor mobility. She had lost her job four months prior to admission to hospital in February 1970 because of the latter.

Physical examination revealed no other relevant abnormality, apart from her gross generalized obesity. She was an extroverted, pleasant woman, who readily stated her preparedness to undergo any procedure which would reduce her weight. Preoperative biochemical investigations (serum electrolvtes, urea, glucose, calcium. magnesium, iron and binding capacity, cortisol, protein bound iodine, vitamin $B_{12}$ and folate) were normal. apart from the serum cholesterol (260 $\mathrm{me} / 100 \mathrm{ml}$ ). Urinary steroids, creatinine clearance, and electrocardiogram were all normal.

On 18 February 1970 I performed a jejunoileostomy. The jejunum was divided 14 in $(35.5 \mathrm{~cm})$ from the duodeno-jejunal junction and the proximal end anastamosed end-to-side to the ileum 4 in $(10 \mathrm{~cm})$ from the ileo-caecal valve. The free end of jejunum was closed and anchored to the base of the mesentery to prevent intussusception. Her postoperative recovery was marred only by a mild degree of wound sepsis and she was discharged home on the sixth postoperative day, weighing $266 \mathrm{lb}$ (121 kg).

During the ensuing ten months she has lost weight steadily to $196 \mathrm{lb}(89.1 \mathrm{~kg})$ in December 1970. There has been no evidence of psychological disturbance, and she is delighted with the result. Her breathlessness and backache in particular have remitted, and she is totally free of the dietary worries which have plagued her for many years. She eats with impunity steak chips, fatty, and other high-calorie foods until satiated, and there has been at no time any problems of diarrhoea. Her only difficulty has been in flushing down the lavatory her once daily fatty stools. The three-day faecal fat output is $25.8 \mathrm{~g}$, and the only other biochemical abnormalities which have come to light at her regular monthly examinations have been a fall in serum albumin from a preoperative mean of $4.4 \mathrm{~g} / 100 \mathrm{ml}$ to $3.6 \mathrm{~g} / 100 \mathrm{ml}$, and the serum iron, which now ranges from 60 to $80 \mu \mathrm{g} / 100$ $\mathrm{ml}$. Serum cholesterol has declined to 175 $\mathrm{mg} / 100 \mathrm{ml}$. Her only medication throughout the postoperative period has been iron and multivitamin therapy.

The result to date has been very satisfactory, and there appears to be no need to reverse the intestinal short circuit. It is planned to admit her to hospital again in January 1971 for full metabolic reassessment prior to removal or her large fatty apron and repair of an old nephrectomy incisional hernia.

A hazard of jejuno-ileal shunt appears to be a psychiatric disturbance, usually a depressive state, seen in a small number of patients. For this reason the selection of patient for the operation should include a full psychiatric assessment. Otherwise, potential complications such as intussusception volvulus, and metabolic deficiencies can be prevented by care at operation and by regular postoperative monitoring. Diarrhoea is not usually a problem as the ileocaecal valve is not bypassed.

Though physicians express some scepticism and reluctance to recommend operative treatment of gross intractable obesity, there is little doubt that in well selected patients this quite simple operation is a very effective and rewarding form of management.-I am, etc.,

General Hospital,

Michael Badeley

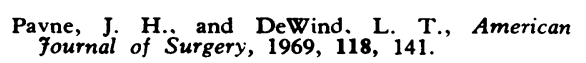

\section{Penicillin Instability in Infusions}

SIR,-YYour leading article (5 December 1970 , p. 571) drew attention to the important questions of drug stability in intravenous infusion solutions and of possible chemical interaction between drug which are added to such infusions. This is undourbtedly an area where a good deal more research is needed.

Detailed information on the stability of the semisynthetic penicillins in eight infusion solutions was published earlier this year.' Furthermore, in conjunction with colleagues in hospital pharmacy, we are at present engaged on an extensive programme of assays to study the effects of mixing other drugs with penicillins in a range of intravenous media. Such assays are essential for the detection and measurement of interactions, which are often unaccompanied by visual changes. For example, methicillin undergoes $15-20 \%$ inactivation in five minutes when mixed with kanamycin at intramuscular concentrations, though the solution remains clear. We have also found that ampicillin, methicillin, and carbenicillin should not be added to dextrose or saline infusions containing $0.02 \%$ hydrocortisone sodium succinate, though cloxacillin is unaffected by the latter.

Your article also discussed a recent paper which reported accelerated decomposition of several penicillins in solutions of carbohydrate buffered to $\mathrm{pH}$ 8.5-8.9 with 0.05 or $0.075 \%$ sodium bicarbonate compared with solutions of carbohydrate or bicarbonate separately. ${ }^{2}$ As far as I am aware, the use of mixed dextrose/bicarbonate solutions is unusual in Britain, so that the observed effect, though interesting, if of marginal relevance to routine infusion practice. The inactivation was also accentuated by the fact that the experiments were performed at $37^{\circ} \mathrm{C}$ rather than at room temperature Ampicillin should in case be infused within four hours in dextrose or dextrose saline, and methicillin within five to six hours, though carbenicillin, cloxacillin, and flucloxacillin are very stable in these media. Carbenicillin and methicillin are relatively stable in $1.4 \%$ sodium bicarbonate solution, but ampicillin should be infused within six hours and cloxacillin within eight hours in this fluid.-I am, etc.,

BRIAN LYNN

Head of Medical Informat:on and Services Beecham Pharmaceutical Division, Brentford, Middx

Lynn, B., Fournal of Hospital Pha:macy, 1970 Simberk off, M. S. Thomas. L. McGregor, D.
Shonkein, I., and Levine, B. B.. New England fhonkein, I., and Levine, B. B.. New England

SIR,-Having recently encountered a patient reminiscent of cases reported by Dr. P. J. Watkins and others (10 October, p. 89), we wish to submit a brief report.

A 23-year-old woman was admitted with a five-day history of severe cough and malaise followed by nausea, vomiting, and diarrhoea for 24 hours prior to admission. Her blood pressure was $100 / 40$, pulse 168 , respiration rate 40 . She was confused and her face was flushed. An acetone breath was noted.

Blood sugar was $709 \mathrm{mg} / 100 \mathrm{ml}$, sodium $147 \mathrm{mEq} / 1$, potassium 3.5 , chloride $111, \mathrm{CO}_{2}$ content 15, pH 7.20, and $\mathrm{PCO}_{2} 36.4 \mathrm{~mm} \mathrm{Hg}$. Two hours after the blood was drawn for these determinations cardiac arrest occurred. She had received 120 units of insulin, $45 \mathrm{mEq}$ of sodium bicarbonate, and 11 . of normal saline. The patient did not recover. Chest $x$-ray films were nøgative. An E.C.G. had revealed supraventricular tachvcardia of 200 per minute. Peaked P waves that merged with tall $T$ waves were present. The course of events suggests that the patient succumbed to hypokalemia. There was no previous history of diabetes mellitus.

The $\mathrm{PCO}_{2}$ was higher than expected for a simple metabolic acidosis. All four of the patients with $\mathrm{PCO}_{2}$ values reported in the paper by $\mathrm{Dr}$. Watkins and his colleagues presented respiratory insufficiency superimposed on metabolic acidosis. Blood $\mathrm{pH}$ of 13 of their 29 patients was less than 7.1. Such severe acidosis may have been the result of inadequate respiratory compensation in diabetic ketoacidosis.

This suggests to us the possibility that severely depleted total body potassium, whatever its cause, may prevent adequate respiratory compensation in metabolic acidosis. Special attention should be directed to serum potassium levels in diabetic ketoacidosis when $\mathrm{PCO}_{2}$ values are higher than expected for a pure metabolic acidosis.-We are, etc.,

Charles K. Tashima IVo KaLACIC Danilo Deano

Department of Medicine,

Chicago, Ill., U.S.A 